\title{
Identification of a Family of Extensin-Like Glycoproteins in the Lumen of Rhizobium-Induced Infection Threads in Pea Root Nodules
}

\author{
Elizabeth A. Rathbun, Michael J. Naldrett, and Nicholas J. Brewin \\ John Innes Centre, NR4 7UH Norwich, England
}

Submitted 6 August 2001. Accepted 22 December 2001.

\begin{abstract}
Rhizobium leguminosarum bv. viciae normally gains access to pea host cells through tubular cell wall ingrowths termed infection threads. Matrix glycoprotein (MGP), a major component of the infection thread lumen, is also secreted from the tips of uninoculated roots and can be released into solution under reducing conditions. Monoclonal antibody MAC265, which recognizes MGP through a carbohydrate epitope, was used for immunoaffinity purification of the glycoprotein from pea roots. Following treatment with chymotrypsin, a peptide fragment was obtained and subjected to $\mathbf{N}$-terminal sequencing. Using PCR primers based on this sequence, cDNA clones were isolated with RNA from inoculated roots and nodules. DNA sequencing of 30 of these clones revealed a family of closely related and repetitive polypeptides with (hydroxy)proline-rich motifs. The cDNA sequences showed over $70 \%$ identity with the deduced amino acid sequences of plant extensins, particularly with VfNDS-E from Vicia faba and MtN12 from Medicago truncatula, both of which are strongly upregulated in legume root nodules. Root nodule extensins from pea were of variable length but showed strong sequence conservation of the N-terminus, of the C-terminus, and of a central domain comprising 33 amino acids that were sometimes reiterated. The distribution of tyrosine residues suggested the possible importance of intramolecular and intermolecular cross-linking. There was strong sequence conservation with MtN12 in the $3^{\prime}$-untranslated region, suggesting a possible involvement in posttranscriptional regulation of gene expression.
\end{abstract}

Additional keywords: Pisum sativum, symbiosis, nitrogen fixation.

Most members of the legume family, Fabaceae, (Sprent 2001) establish a nitrogen-fixing symbiosis with rhizobial species Rhizobium, Sinorhizobium, Bradyrhizobium, Azorhizobium, Methanorhizobium, and others (Moulin et al. 2001; Spaink 2000). In these bacteria, a set of genes (nod genes) is transcriptionally activated in response to flavonoids secreted by legume roots. The nod genes act cooperatively to synthesize lipochitin oligosaccharides (Long 1996). These signal molecules act as morphogens and mitogens, stimulating root hair deformation and cortical cell division in the appropriate leg-

Corresponding author: N. J. Brewin; E-mail: nick.brewin@bbsrc.ac.uk; Telephone +44 01603 450273; Fax: +44 01603450045

Nucleotide sequence data reported are available in the GenBank database under the accession numbers AF397026 through AF397033. ume host (Schultze and Kondorosi 1998; Stougaard 2000). Subsequently, tissue and cell colonization by rhizobial bacteria lead to the development of functional root nodules within which symbiotic nitrogen fixation takes place (Brewin 1991).

In pea, the microsymbiont Rhizobium leguminosarum bv. viciae gains entry to host root tissues through tip-growing infection threads, which are tubular ingrowths of the plant cell wall (Brewin 1998). The infection thread initiates following growth of bacteria in close association with a deformed root hair cell wall (Rae et al. 1992). Infection is propagated from cell to cell because transcellular threads are reinitiated in adjacent cells in the root cortex (Van Brussel et al. 1992) and subsequently, in the invasion zone of the developing nodule. A similar process is observed in alfalfa and other temperate legumes (Gage et al. 1996; Pellock et al. 2000). The lumen of the infection thread is topologically equivalent to an intercellular space, and the luminal matrix apparently shares many components with the extracellular matrix (Rae et al. 1992). Here, we describe the isolation and characterization of one of these components that was originally identified in the lumen of the infection thread using a monoclonal antibody.

Rat monoclonal antibody MAC265 recognizes a plant glycoprotein that could be isolated from fractionated pea nodule extracts and was localized to the infection thread lumen by immunogold staining (Bradley et al. 1988). Other monoclonal antibodies (MAC204 and MAC236), developed in the same screen against fractionated pea nodules, apparently recognize the same class of matrix glycoprotein (MGP) comigrating at 100 to $110 \mathrm{kDa}$ (VandenBosch et al. 1989). In each case, the sensitivity of the antibody-antigen interaction to periodate oxidation indicated that the antibody probably recognized a carbohydrate epitope. MAC265 antigen is also found in intercellular spaces and in the walls of rapidly expanding root cortical cells (Rae et al. 1991, 1992). It is also a component of root-tip slime (Wisniewski et al. 2000). These observations indicate that the composition of the infection thread lumen resembles that of the extracellular matrix.

The solubility of MAC265 antigen (i.e., its extractability from tissues) is apparently reduced by hydrogen peroxide (Bradley et al. 1992; Wisniewski et al. 2000). Furthermore, the apparent molecular mass may be changed as a result of protein cross-linking, as indicated by the fact that these antigens often have different apparent molecular masses following isolation from different tissues of pea (Bradley et al. 1988) and from different legumes, e.g., lupin (de Lorenzo et al. 1998). These preliminary observations suggest that protein crosslinking may be an important factor controlling the fluidity of the matrix material that surrounds rhizobia in the infection thread lumen. 
In the present study, we describe the isolation of MGP by immunopurification from pea root exudate. There are two reasons for not choosing nodules as the source of MGP antigen. First, the volume of infection threads is considerably less than $1 / 1,000$ part of nodule volume. Second, the evidence of Wisniewski and associates (2000) and Higashi and associates (1987) suggests that most of the MGP present in infection threads is probably insoluble as a result of peroxide-driven protein cross-linking and, therefore, it is likely to be nonextractable. Following immunopurification of MGP, it was possible to obtain peptide sequence information and to amplify cDNA products by PCR-based cloning. We report that MAC265 recognizes a family of extensin-type glycoproteins, and we discuss the possible significance of these matrix components in the structure and development of infection threads.

\section{RESULTS}

\section{Cellular and tissue distribution of MAC265 antigen.}

Immunogold localization studies (Fig. 1) identified MAC265 antigen (MGP) as a major component of the infection thread lumen, confirming previous observations (Rae et al. 1991). The antigen is also released from the root tips of uninfected pea seedlings, provided that antioxidant conditions are maintained (Wisniewski et al. 2000). Western immunoblotting (Fig. 2) suggested that the MGP antigens isolated from uninfected root tips were indistinguishable from those derived from nodule extracts (Fig. 2A and B). Therefore, the seedling root system was adopted as a convenient source of the larger quantities of MGP needed to obtain amino acid sequence information.

\section{Immunopurification of MAC265 antigen MGP.}

For best recovery from seedling roots, extraction buffer contained reducing agents (dithiothreitol and ascorbate) and a chelating agent (EDTA). Following sodium dodecyl sulfatepolyacrylamide gel electrophoresis (SDS-PAGE), the immunopurified MGP appeared as a doublet after silver staining, comigrating at 100 to $110 \mathrm{kDa}$ (Fig. 2C). However, these bands stained poorly with Coomassie Blue (data not shown). MAC265 labeling of the same material on a Western blot showed the doublet plus several bands with smaller molecular masses (Fig. 2D) and, more rarely, a band of approximately $175 \mathrm{kDa}$ (not shown).

A sample of purified MGP was subjected to Fourier transform infrared (FTIR) analysis (Fig. 3). Amide-stretching bands of protein occur at 1,650 and $1,550 \mathrm{~cm}^{-1}$ and a region of carbohydrate 'fingerprint' trace is indicated between 1,200 and 900 $\mathrm{cm}^{-1}$ (McCann et al. 1997). This provides further evidence that the MAC265 antigen is a glycoprotein. The carbohydrate content of the glycoprotein is estimated at $70 \%$ of molecular mass (M. McCann, personal communication).

\section{Chymotryptic digestion and peptide sequencing.}

Initial attempts to obtain peptide sequences from immunopurified MGP gave disappointing results, probably as a result of $\mathrm{N}$-terminal blocking of the protein. In order to obtain peptide fragments, the purified MGP was treated with excess chymotrypsin for $16 \mathrm{~h}$. This treatment reduced the $110 \mathrm{kDa}$ doublet and altered the pattern of the smaller molecular mass bands. In particular, a novel antigen band $(40 \mathrm{kDa})$ was identified after enzyme digestion (Fig. 2E) and used for peptide sequencing. Immunopurified MGP from over 3000 pea seedlings was pooled and, after further concentration and digestion with chymotrypsin, enough material (fmoles) was obtained from the 40$\mathrm{kDa}$ band to yield the sequence of 26 residues shown in Figure 4A. Sequencing of a second, larger molecular mass band from the same blot confirmed the first 10 residues (data not shown).
Using the 26-amino acid chymotryptic peptide (mgp-chtr) with the BLASTP algorithm (Altschul et al. 1997), a search of databases revealed $83 \%$ identity (Fig. 4B) with the deduced amino acid sequence of an extensin clone isolated from the cDNA of Vicia faba nodules (Perlick and Pühler 1993). There was $72 \%$ identity with the translated sequence of another nodule extensin clone, MtN12, from Medicago truncatula (Gamas et al. 1996). Confirmation that the MGP is an extensin was obtained using LM1, a monoclonal antibody that recognizes carrot extensin (Smallwood et al. 1994). LM1 and MAC265 gave similar patterns of immunostaining on Western blots (Fig. 2D and F) and on root-tip material (data not shown).

\section{cDNA cloning.}

Clones were isolated from RNA sequences derived from inoculated pea roots by 3'-rapid amplification of cDNA ends (RACE) (Frohman et al. 1988) with primers PER1 and PER2 (Fig. 4B). Following cDNA sequencing, the deduced aminoacid sequence was determined for 13 clones, and in all cases, the presence of the chymotryptic peptide sequence (Fig. 4) was confirmed. Using nodule cDNA and reverse primers designed

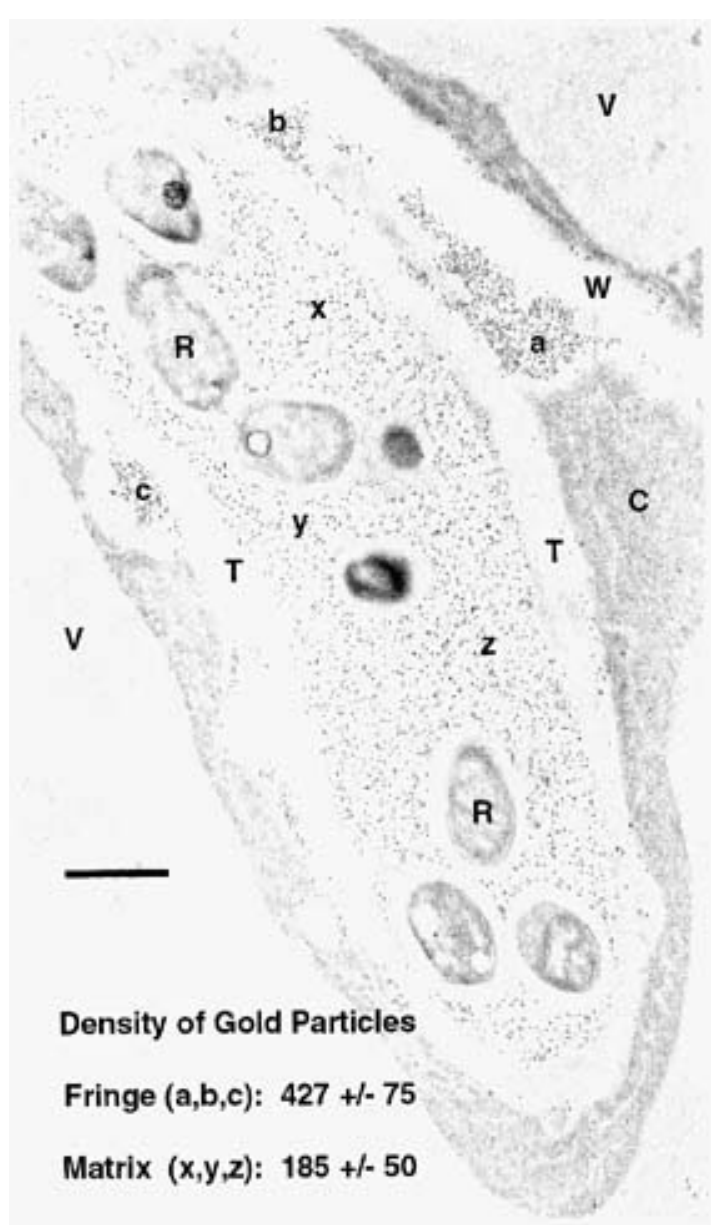

Fig. 1. Immunogold localization of MAC265 antigen (matrix glycoprotein) in the lumen of an infection thread. Ultrathin section of infected host cell taken from the sub-apical tissue of a pea root nodule. $\mathrm{W}=$ cell wall, $\mathrm{C}=$ cytoplasm, $\mathrm{T}=$ infection-thread wall, $\mathrm{R}=$ rhizobial cells (each surrounded by a capsule of extracellular polysaccharide), $\mathrm{V}=$ vacoule, $B a r=1 \mu \mathrm{m}$. Inset shows the mean density $( \pm$ standard deviation) per $\mu \mathrm{m}^{2}$ of $15 \mathrm{~nm}$ colloidal gold particles, sampled at the fringe (regions $\mathrm{a}, \mathrm{b}$, and $\mathrm{c}$ ) and in the lumen (regions $\mathrm{x}, \mathrm{y}$, and $\mathrm{z}$ ) of the infection thread. The higher density of labeling at the margins of the infection-thread wall indicates that targeted secretion of matrix glycoprotein could be a factor contributing to the growth of the infection thread. Electron micrograph courtesy of D. J. Sherrier. 
from conserved regions of cloned MGP cDNA, four more clones were obtained by $5^{\prime}$-RACE (Table 1 ). A further 12 clones were isolated from inoculated and uninoculated pea root cDNA by reverse transcription (RT)-PCR, using primers PER13 and PER15 (Table 1). Sequence analysis showed that these clones encoded closely related members of an extensin gene family.

In all cases, the coding sequences exhibited a complex (hydroxy)proline-rich repetitive nature typical of extensin genes. No two clones were exactly the same length, with some sequences showing gaps when aligned. There were also some codon switches, e.g., between alanine and valine at some positions and between serine and proline at another position. Third base codon redundancies were also common. All of the clones obtained by 5'-RACE or reverse transcription-polymerase chain reaction (RTPCR) had probable start sequences similar to the start sequences of published extensins (data not shown).

Two lines of evidence indicate that the 40-kDa band that was sequenced was an internal peptide of the $100-$ to $110-\mathrm{kDa}$ band (Fig. 2). First, the evidence from $3^{\prime}$ - and 5'-RACE products consistently indicated that the $\mathrm{N}$-terminal sequence obtained corresponded to an internal fragment of the predicted polypeptide, and moreover, that the sequence was always preceded by a Tyr residue that would have been the target for chymotrypsin digestion. Second, when the undigested material from the 110$\mathrm{kDa}$ band was sequenced, we obtained evidence for Asn-GlnTyr, followed by some very poor-quality sequence information. This corresponded very closely to the predicted amino acid sequence for the N-terminus encoded by the cDNA clones (AsnGln-Tyr-Ser-Tyr-Ser-Ser-Pro-Pro-Pro-Pro), following cleavage of the leader peptide at the site predicted by computer analysis (Emanuelsson et al. 2000; Nielsen et al 1997).

Figure 5 shows the deduced amino acid sequences of eight cDNA clones that are representative of those obtained by $3^{\prime}$ RACE, 5'-RACE, and RT-PCR (designated 3.x, 5.x, and .RTx, respectively). As explained in the next section, these sequences have been aligned on the basis of three perceived regions of consensus: N-terminal, central, and C-terminal.

\section{Sequence alignments and conserved motifs.}

Based on all the cDNA sequence information obtained (Fig. 5), a generalized domain structure for nodule extensins is presented in Figure 6. The 60-residue N-terminal conserved domain comprises a 27-residue leader peptide followed by a $33-$ residue extensin motif that is not repeated elsewhere in the open reading frame. Minor variations in the start sequences exist, and in one clone (PsEXT.RT3), the second half of the region is missing (from residue 39 onward). Clone PsEXT5.5 contains the motif $\mathrm{SP}_{7}$ instead of motif $\mathrm{SP}_{5}$.

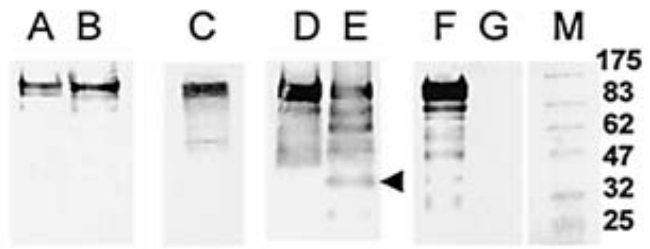

Fig. 2. Analysis of MAC265 antigen after sodium dodecyl sulfatepolyacrylamide gel electrophoresis. Lanes A and B, Western blot showing MAC265 antigen in extracts from roots and nodules, respectively. Lane C, Concentrated immunopurified MAC265 antigen visualized by silver staining. Lanes $\mathrm{D}$ and $\mathrm{E}$, Western blot showing MAC265 antigen before and after, respectively, treatment with chymotrypsin. Arrowhead indicates the position of the $40-\mathrm{kDa}$ band that was used for $\mathrm{N}$-terminal sequencing. Lanes $\mathrm{F}$ and $\mathrm{G}$, Immunostaining of immunopurified antigen with the antiextensin antibody LM1 and negative control, respectively, with no primary antibody. Lane M, Molecular mass markers are indicated in kDa.
The central domain consists of 33 residues and includes the original mgp-chtr peptide in all eight clones. This region is tandemly repeated (with minor variations) in four of the clones. Furthermore, it can be divided into two motifs that are reiterated in other parts of the extensin sequence: Motif I, Thr-ProHis-Lys-Lys-Pro-Tyr-Lys-Tyr-Pro-Ser-(Pro) 5 , is also present within the C-terminal domain (discussed below). Motif II, ValHis-Thr-Tyr-Pro-His-Pro-His-Pro-Val-Tyr-His-Ser-(Pro) ${ }_{4}$, is repeated more often, being found as a variable number of reiterations between the $\mathrm{N}$-terminal and central consensus regions and between the central and $\mathrm{C}$-terminal consensus regions. Thus, the variable number of reiterations of Motif I, together with the tandem repeat of the central domain, appears to be the major factor affecting the overall size of the extensin sequence.

The C-terminal domain comprises 56 conserved amino acids immediately preceding the stop codon. The sequence is identical in all clones, except for a single valine/alanine switch in two instances. This region is not repeated elsewhere, although it does contain 16 amino acids (Motif I) that are reiterated within the central region (discussed above).

It was interesting to note that conservation of the cDNA sequence extended beyond the coding sequence into the $3^{\prime}$-untranslated region (UTR) of the $3^{\prime}$-RACE clones (data not shown). These sequences were not identical. There were some gaps, and clones tended to fall into groups. Furthermore, comparisons of the $3^{\prime}$-UTRs of pea MGP extensins with those of MtN12 from Medicago truncatula showed over 91\% identity with one group. This is demonstrated by the comparison of PsEXT3.2 and MtN12 3'-UTRs in both the sequence alignment (Fig. 7) and in a diagon plot (Fig. 8).

\section{Expression studies.}

Following Northern (RNA) blotting, the PsEXT3.2 probe labeled a major RNA band of approximately $1.3 \mathrm{~kb}$ in extracts from both roots and nodules, but this was slightly stronger in roots. Both lanes also showed higher molecular weight bands with the most prominent of these running just ahead of the 3.7$\mathrm{kb} 25 \mathrm{~S}$ ribosomal RNA. This band was also stronger in root extracts (Fig. 9B). A smaller probe consisting entirely of $3^{\prime}$ UTRs showed identical but weaker bands (data not shown). Equivalent loading of root- and nodule-derived samples was demonstrated using methylene blue, which stained $25 \mathrm{~S}$ and $18 \mathrm{~S}$ rRNA bands in both roots and nodules (Fig. 9A), and at least one lower band was present in nodules alone that probably represented $16 \mathrm{~S}$ bacteriod rRNA.

In situ hybridization of nodule tissue prints with the same probe showed labeling of the nodule meristem and root cortex

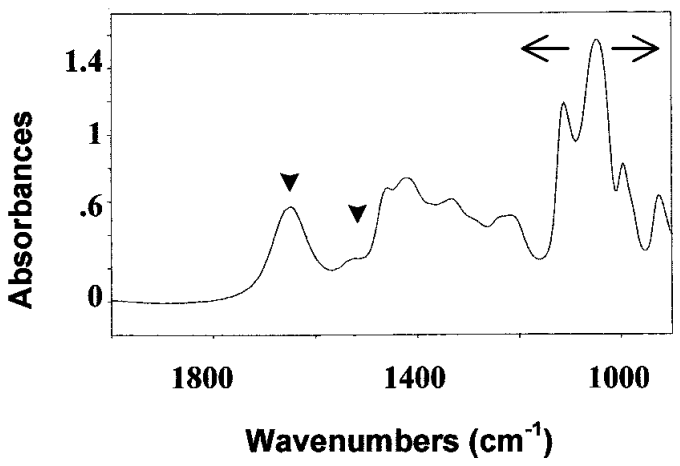

Fig. 3. Analysis of purified MAC265 antigen by Fourier transform infrared spectroscopy. The positions of amide bands are indicated with arrowheads and the region of carbohydrate absorption by arrows. 
or nodule base (data not shown) and is consistent with that seen in $V$. faba nodules with the VfNDS-E extensin cDNA (Perlick et al. 1997).

\section{DISCUSSION}

The monoclonal antibody MAC265 recognizes a carbohydrate epitope associated with a major component of the matrix within infection threads (VandenBosch et al. 1989). Previously, we have reported that this glycoprotein (MGP) can be extracted from pea root tips and that it can be insolubilized by a peroxide-driven process (Wisniewski et al. 2000). Here, we describe how the MAC265 antigen was purified and characterized as an extensinlike glycoprotein on the basis of amino-acid sequence information (Fig. 5) and on the basis of its cross-reaction with LM1 (Fig. 2F), an antibody known to recognize extensins in carrot (Smallwood et al. 1994). As expected for an extensin, FTIR spectroscopy (Fig. 3) indicated that MGP is a heavily glycosylated glycoprotein, which might be one reason why it stains so weakly with Coomassie Blue. There is an obvious discrepancy between the apparent molecular mass of the MAC265 antigen on SDS-PAGE (100 to $110 \mathrm{kDa}$ ) and the molecular mass of the polypeptide(s) encoded by the cDNAs $(20$ to $25 \mathrm{kDa}$ ) and predicted by the size of hybridizing mRNA identified by Northern blotting ( 1 to $1.3 \mathrm{~kb}$ ). There are several possible reasons for this anomolous migration: protein crosslinking and dimerization, abnormal electrophoretic mobility arising from the high proline content, and the influence of the high carbohydrate content.

Extensins are an abundant and diverse family of cell wall glycoproteins (Baumberger et al. 2001; Showalter 1993; Sommer-Knudsen et al. 1998). However, the sequences of the cDNAs isolated in the present study represent a very closely related subgroup characterized by several conserved and reiterated peptide motifs (Fig. 6). MGP as an extensin corresponds most closely to the deduced amino acid sequence of an extensin from $V$. faba, VfNDS-E, and MtN12 from Medicago truncatula (Gamas et al. 1996), both of which are apparently upregulated in nodules relative to root tissues. We have found this family of extensins only in legumes (pea, Medicago spp., lupin, soybean, Sesbania spp., etc). Hence, there is an obvious correlation between this group of cell wall glycoproteins and the capacity for nodulation. This connection is reinforced by the topological localization of MGP within the lumen of infection threads. Therefore, we propose to term this subclass of extensins "root nodule extensins".

Extensin antigens recognized by MAC265 have previously been identified in elongating or expanding root cells (Rae et al. 1991), and therefore, their involvement in infection thread development is consistent with a more general role in facilitating cell wall growth and expansion. Furthermore, enhanced secretion of the glycoprotein has been correlated with the earliest stages of infection thread initiation in root hairs of $V$. hirsuta. This begins at the point of inception of the infection thread in

Table 1. Primers used for $3^{\prime}$ - and $5^{\prime}$-RACE and amplification of reverse transcription-polymerase chain reaction products ${ }^{\mathrm{a}}$

\begin{tabular}{|c|c|c|}
\hline Primer & Sequence & Reference \\
\hline G1149 & $\begin{array}{l}\text { CTC GAG GAT CCG CGG CCG } \\
\text { C(T) }\end{array}$ & Vincent et al. 2000 \\
\hline G1187 & GCT CGA GGA TCC GCG GC & $\begin{array}{l}\text { Kardailsky and Brewin } \\
1996\end{array}$ \\
\hline PER $1^{\mathrm{b}}$ & $\begin{array}{l}\text { GTN CAY ACN TAY CCN CAY } \\
\text { CCN CAY CC }\end{array}$ & This paper \\
\hline PER $2^{b}$ & $\begin{array}{l}\text { ACN CCN CAY AAR AAR CCN } \\
\text { TAY AAR TAY CC }\end{array}$ & This paper \\
\hline PER3 & $\begin{array}{l}\text { TTA GAT CCA TAT AGT GTG } \\
\text { ATG CCA }\end{array}$ & This paper \\
\hline PER4 & $\begin{array}{l}\text { AGG GTA GGT GTG AGC TGG } \\
\text { TGG }\end{array}$ & This paper \\
\hline PER13 & $\begin{array}{l}\text { AAT GAG GTC CCT AAT GGC } \\
\text { CTC T }\end{array}$ & This paper \\
\hline PER15 & $\begin{array}{l}\text { ATA GTG TGA TGC CAA TGA } \\
\text { TGT GC }\end{array}$ & This paper \\
\hline
\end{tabular}

\footnotetext{
${ }^{a}$ All sequences are written $5^{\prime}$ to $3^{\prime}$.

${ }^{b}$ Ambiguity symbols follow the standards of the International Union of Biochemists.
}

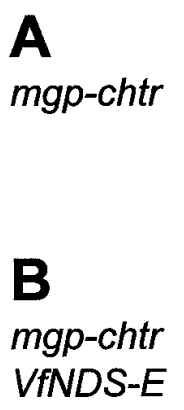

VfNDS-E

KYPxOOOOOVHTYPH (P) H (P) VYq (x) OOOO (O) (O/V) (K)

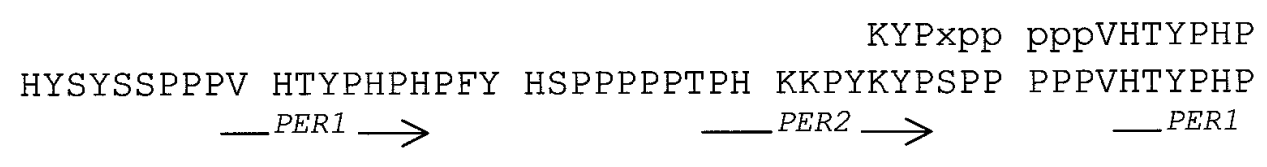

\section{mgp-chtr \\ VfNDS-E}

HPVYqXpppp

HPVYHSPPPP PTPHKKPYKY PSPPPPPVHT YPPHVPHPVY HSPPPPVYSP

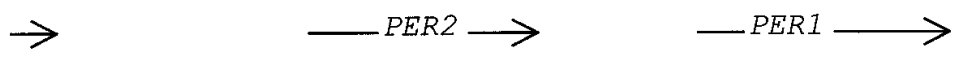

mgp-chtr

VFNDS-E

Fig. 4. N-terminal sequence of a 40-kDa chymotryptic fragment (mgp-chtr) derived from immunopurified MAC265 antigen. A, Results from 26 cycles of peptide sequencing. O represents substituted hydroxyprolines, $x$ represents a blank cycle with no residue detected (presumed to be either cysteine or serine), q represents the point where the sequencing run was paused and restarted, and parentheses indicate residues that gave weak or uncertain peaks. B, Comparison with deduced amino acid sequence for VfNDS-E (Perlick and Pühler, 1993). Primers PER1 and PER2 (used for 3'-RACE) were designed as redundant oligonucleotides encoding the repeating peptide motifs as indicated by the arrows. 
the deformed root hair cell (Rae et al. 1992) and continues throughout the subsequent growth and development of infection threads (Fig. 1). It is difficult to prove that the very tip of the infection thread is the target for secretion of extensin. However, this seems probable in view of the fact that infection threads with very thin cell walls generally have more MGP and fewer bacteria, relative to the lumens of more mature infection threads. Root nodule extensin is thus a key component of the extracellular matrix, and we hypothesize that its physical and biochemical properties (Peters et al. 2000) may have an important influence on the process of tissue and cell colonization by Rhizobium bacteria.

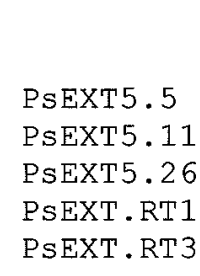

PSEXT5. 5

PsEXT5.11

PsEXT5.26

PsEXT.RT1

PSEXT.RT3

PsEXT3.2

PsEXT3.28

PSEXT3.29

PsEXT5.5

PsEXT5.11

PSEXT5.26

PsEXT.RT 1

PSEXT . RT 3

PSEXT3.28

PsEXT3.29

mgp-chtr
PsEXT3.2

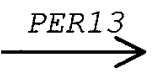

MRSLMASAAL ILALAMLFLS FPSEISANQY SYSSPPPPVH SPPPPKDPHH MRSLMASASL TLALAILEFS FPSEISANQY SYSSPPPPVH SPPPPKDPYH MRSLMASASL TLALAILFES FPSEISANQY SYSSPPPPVH SPPPPKDPYH MRSLMASAAL ILALAMLELS EPSEISANQY SYSSPPPPVH SPPPPKDPHH MRSLMASAAL ILALAMLELS FPSEISANQY SYSSPPPP.........

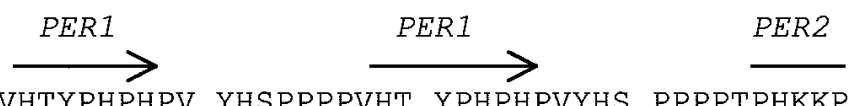

YSSPPPPPPP VHTYPHPHPV YHSPPPPVHT YPHPHPVYHS PPPPTPHKKP YSSPPPPP.. VHTYPHPHPV YHSPPPPVHT YPHPHPVYHS PPPPTPHKKP YSSPPPPP.................. YHT YPHPHPVYHS PPPPTPHKKP YSSPPPPP.. VHTYPHPHPV YHSPPPPVHT YPHPHPVYHS PPPPTPHKKP

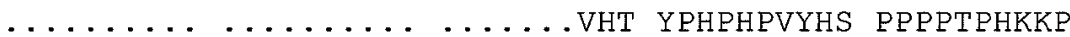

TPHKKP TPHKKP

PHKKP

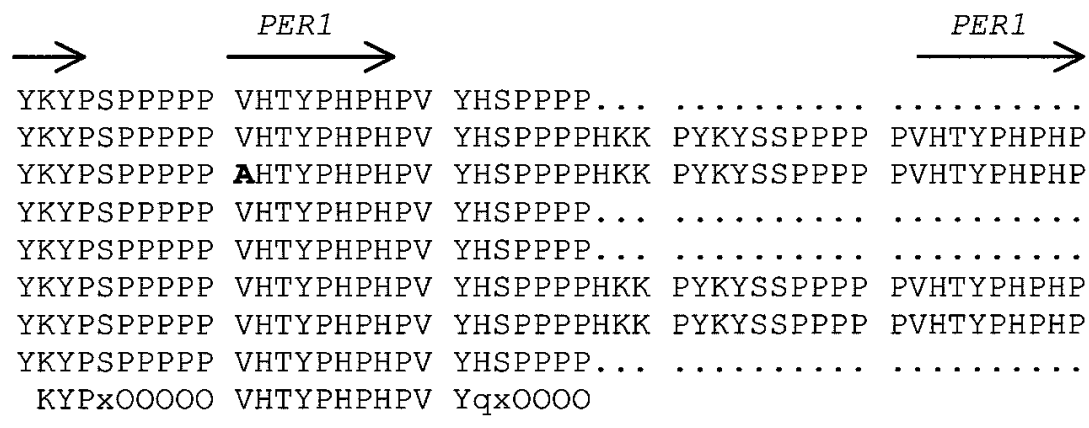

\section{PER2}

PSEXT 5.5

PSEXT5.11

PsEXT5.26

PSEXT.RT1

PSEXT.RT3

PSEXT3.2

PsEXT3.28

PsEXT3.29

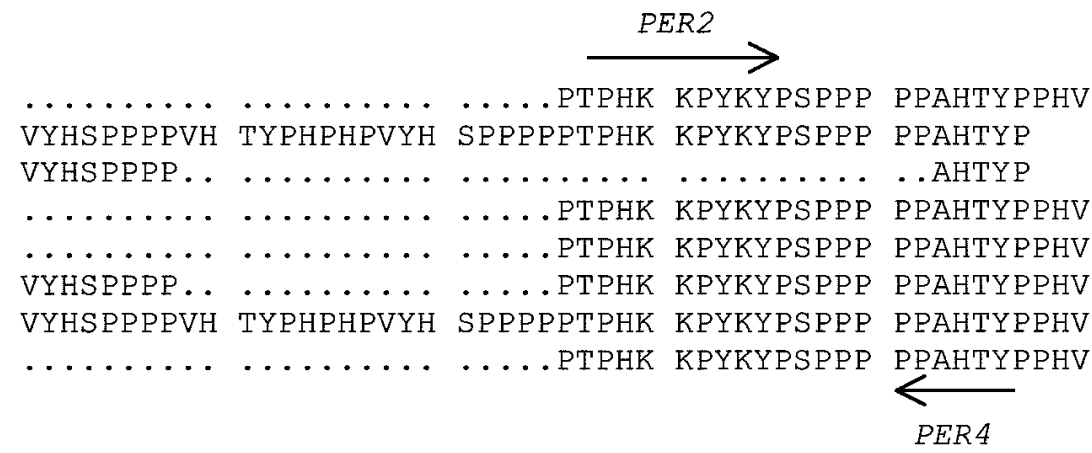

PSEXT 5.5

PSEXT.RT1

PsEXT.RT3

PSEXT3.2

PsEXT3. 28

PsEXT3. 29
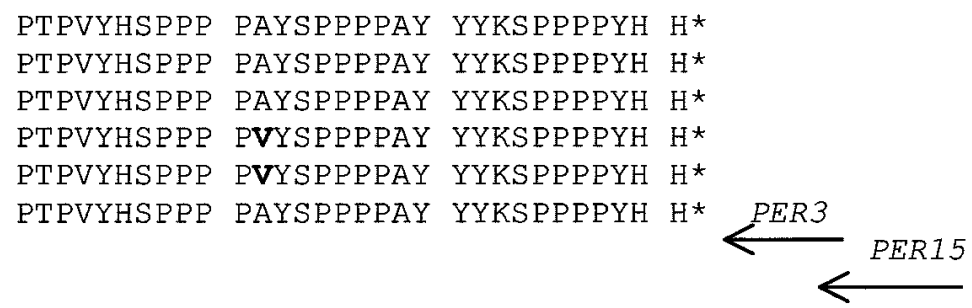

Fig. 5. Deduced amino acid sequences derived from cDNA clones encoding pea matrix glycoprotein extensins. Sequences derived from $3^{\prime}$-RACE are prefixed with 3 and those from $5^{\prime}$-RACE are prefixed with 5. 'RT' clones are the products of reverse transcription-polymerase chain reaction using genespecific primers. The positions of the primers used (labeled PER) are indicated by arrows (discussed in text and Table 1). The presence of the mgp-chtr sequence is shown and valine/alanine deviations are in bold. Sequences are aligned using N-terminal, central, and C-terminal regions of consensus as described in Fig. 6. Gaps caused by the alignment are indicated with dots. The DNA sequences of the PsEXT clones have been deposited in the GenBank database (accession numbers AF397026 through AF397033). 
Plant extensins, hydroxyproline-rich glycoproteins, are important components of the cell wall and are apparently involved in all stages of cell wall formation (Cassab 1998). In the case of root nodule extensins, there are frequent clusters of positively charged residues (with Asn-Gln at the N-terminus and Lys-Lys elsewhere). This might indicate an ability to adhere to negatively charged bacterial surfaces (Bolanos et al. 1996) and perhaps to the borate-pectic network associated with the extracelluar matrix of extending plant cell walls (O'Neill et al. 2001).

Another important characteristic of extensins is that they may be slowly insolubilized in the cell wall by cross-linking, and one possible mechanism for this is through peroxidation (Brady and Fry 1997). In pathogenic interactions, the rapid insolubilization of cell wall extensins may provide a barrier against invading microbes (Bradley et al. 1992). In the Rhizobium-legume symbiosis, the situation is slightly different. There appears to be a fine balance between promotion and prevention of rhizobial colonization in host tissues. The presence of hydrogen peroxide within infection threads has recently been identified cytochemically (Santos et al. 2000, 2001), and even when the host is inoculated with a compatible strain of Rhizobium, a cellular defense reaction similar to the hypersensitive reaction is often observed (Vasse et al. 1993). Thus, the infection of legume roots by Rhizobium bacteria could be described as a controlled pathogenesis in that cellular defense mechanisms similar to the hypersensitive response may be observed. However, in successful infections, these defense responses are either controlled by the plant or overcome by the successful symbiont. In the Rhizobium-legume symbiosis, root nodule extensin (MGP) may have a different function compared to the pathogenic response. By surrounding the bacteria in the infection thread, it may act to limit bacterial growth and also to regulate the growth of the infection thread itself (Wisniewski et al. 2000).

A possible role for MGP in the regulation of tissue and cell invasion has been suggested by a number of previous observations using MAC265 antibody as a probe. Enhanced secretion of MGP by host cells was observed as an early response to Rhizobium infection in pea and Vicia roots (Rae et al. 1991). Furthermore, in nodules induced by lipopolysaccharide-defective strains, abnormal and large intrusion structures were observed, revealing invading bacteria surrounded by abundant and appar- ently overproduced MGP (Perotto et al. 1994). In a parallel study, it was shown that, when suspension cultures of soybean cells were challenged with a fungal elicitor, a structural protein recognized by MAC265 became insolubilized as a result of peroxidemediated oxidative cross-linking (Bradley et al. 1992). Crosslinking of cell wall proteins has subsequently been widely reported as a rapid response to plant pathogens, both in vivo (Otte and Barz 2000) and in vitro (Wojtaszek et al. 1997). ArsenijevicMaksimovic and associates (1997) reported that an extensin gene expressed in root hair cells was downregulated following application of infective Rhizobium strains. However, the sequence of this gene product does not appear to be closely related to the root nodule extensins described in the present study.

The MGP sequences described here exhibit the complex repetitive nature of extensins. Apart from the typical Ser-(Pro) motifs, there are two main repeating units of 16 and 17 amino acids that make up a central region of consensus (Fig. 6). Although there are some variations within the start sequences, the main differences between the clones are due to the presence or absence of these reiterating units. Data from other workers (e.g., Schmidt et al. 1994) suggests that extensinlike proteins can tolerate the loss of integral repeat units and that heterogeneity could result from posttranslational modifications or from closely related genes. In the present study, it is possible that some of the sequence heterogeneity observed may be due to PCR artifacts (Sommer-Knudsen et al. 1998). More probably, it is the result of multiple genomic copies and perhaps is also due to genetic polymorphisms in the pea population used for RNA isolation (Schmidt et al. 1994). Further analysis at the genome level will be needed to define the number of genes encoding nodule extensins.

The presence and the positions of the Ser-(Pro $)_{n}$, other repetitive units and tyrosines in extensins may have functional and structural importance (Kieliszewski and Lamport 1994). For example, the periodicity of the tyrosine residues in the MGP clones (Figs. 5 and 6) might provide scope for intramolecular isodityrosine bridges, while conserved motifs such as Ala-Tyr-Tyr-Tyr-Lys near the C-terminus may be important for intermolecular cross-linking and the formation of di-isodityrosine bridges (Brady and Fry 1997). The final 45 amino acids are almost identical to those in both the Medicago and Vicia extensins MtN12 and VfNDS-E, suggesting either common functionality or evolution, or both.

\title{
N-terminus MRSLMASAALILALAMLFLSFPSEI SANQY SYSSPPP PVHSPPPPKDPHHYSSPPPPP
}

VHTYPHPHPVYHSPPPP

VHTYPHPHPVYHSPPPP

Central

\begin{abstract}
TPHKKPYKYPSPPPPPVHTYPHPHPVYHSPPPP
\end{abstract}
HKKPYKYSSPPPPPVHTYPHPHPVYHSPPPP

VHTYPHPHPVYHSPPPPA

\section{C-terminus}

\section{TPHKKPYKYPSPPPPPAHTYPPHVPTPVYHSPPPPAYSPPPPAYYYKSPPPPYHH*}

Fig. 6. Consensus of translated matrix glycoprotein sequences based on sequence information from $30 \mathrm{cDNA}$ clones shown as standard symbols. The coding sequence is shown from the first $\mathrm{N}$-terminal methionine to the stop codon (*), highlighting (in bold) the conserved $\mathrm{N}$-terminal, central, and $\mathrm{C}$ terminal regions. The central conserved region can be divided into two motifs, each of which is reiterated in other parts of the sequence. Motif I, Thr-ProHis-Lys-Lys-Pro-Tyr-Lys-Tyr-Pro-Ser-(Pro), is also present within the C-terminal domain. Motif II, Val-His-Thr-Tyr-Pro-His-Pro-His-Pro-Val-Tyr-HisSer-(Pro $)_{4}$, is repeated more often. It is found as a variable number of reiterations between the N-terminal and central consensus regions and between the central and C-terminal consensus regions. The reiterated motifs flanking the central region are shown in this alignment but are not present in all clones. Variant residues are underlined and blocks of Ser-(Pro $)_{4}$ or Ser-(Pro $)_{5}$ are shaded. The predicted cleavage site following a 27 -amino acid leader peptide is indicated by an arrowhead (Emanuelsson et al. 2000; Nielsen et al 1997). 
The large degree of identity within the $3^{\prime}$-UTR of the pea (MGP) and Medicago (MtN12) extensins (Figs. 7 and 8) is a further indication that these genes are closely related and may share a common system of posttranscriptional regulation (Derrigo et al. 2000). Preliminary indications from computer analysis (Crespi et al. 1994) indicate that the $3^{\prime}$-UTR sequence for root nodule extensin mRNA apparently contains a strong structural motif (M. Crespi, personal communication).

Although MtN12 was originally isolated as a nodule-enriched transcript, our studies of transcript abundance in pea demonstrate no significant difference between nodule extracts and roots (including root tips). Results of in situ hybridization with tissue-printed pea nodules gave distributions that were essentially similar to those previously described for $V$. faba. This mRNA distribution pattern is entirely consistent with the known distribution of MGP in the nodule invasion zone and also in the inner region of uninfected parenchyma, as previously localized by MAC265 (Rae et al. 1991, 1992).

Previous studies have localized a family of proline-rich glycoproteins to the lumen of infection threads (Sherrier and VandenBosch 1994). The antisera used in that study apparently recognized polypeptides similar in composition to PsENOD12, a nodule-enhanced gene product closely associated with the onset of infection thread development (Scheres et al. 1990a). While the cytological distribution of these proline-rich proteins was apparently very similar to that of MAC265 antigen, the deduced polypeptide sequence for root nodule extensin is quite distinct from PsENOD12. The only shared motif is Pro-HisLys-Lys which, in the case of nodule extensin, forms part of a large sequence Pro-His-Lys-Lys-Pro-Tyr-Lys-Tyr (Fig. 6).

Other plant components that may be associated with infection thread development have been identified by transcript expression studies, e.g., the putative arabinogalactan protein encoded by PsENOD5 (Scheres et al. 1990b), or by immunocytology, e.g., the identification of lipoxygenase (Gardner et al. 1996) and diamine oxidase antigens (Wisniewski et al. 2000).
The increasing application of plant mutational analysis will help to identify genetic lesions associated with infection thread initiation and development (Schauser et al. 1999), although genes such as root nodule extensin that are present in multiple copy may be difficult to analyze by mutational approaches.

\section{MATERIALS AND METHODS}

Plant culture, inoculation, and tissue blotting.

Seeds of Pisum sativum cv. Frisson were surface sterilized in $70 \%$ (vol/vol) ethanol for $30 \mathrm{~s}$ followed by commercial bleach (less than $5 \%$ available chlorine) for $7 \mathrm{~min}$. They were rinsed with sterile water and germinated in the dark at $20^{\circ} \mathrm{C}$ on agar containing Fahraeus (FP) medium (VandenBosch et al. 1989). For the production of nodules, plants were grown in flasks containing FP agar medium and were inoculated 7 days post imbibition with Rhizobium leguminosarum bv. viciae strain 3841 (Wang et al. 1982). The bacteria were cultured in tryptone yeast (TY) medium, and inoculation was as described by Wood and associates (1989).

For the isolation of MGP, approximately 300 plants were grown on FP agar in petri dishes for 4 days (in the dark) until the roots were between 3 and $5 \mathrm{~cm}$. The seedlings were transferred to a wire rack with the roots suspended in $200 \mathrm{ml}$ MGP extraction buffer (50 mM Tris- $\mathrm{HCl}, \mathrm{pH} 7.4,10 \mathrm{mM}$ ascorbate, $10 \mathrm{mM}$ dithiothreitol, $10 \mathrm{mM}$ EDTA), covered loosely with aluminum foil, and incubated overnight with gentle agitation on a rotary platform at room temperature. To check for the presence of MAC265 antigen at the root tips and in the exudate, sample roots were blotted onto a sheet of dry nitrocellulose (Schleicher and Schuell, Dassel, Germany) and removed after a few seconds. Dots $(1 \mu \mathrm{l})$ of root exudate were added, and the nitrocellulose was assayed with MAC265 (as for Western blotting).

Nodules were removed from roots 2 weeks postinoculation and either used immediately or frozen at $-70^{\circ} \mathrm{C}$.

\begin{abstract}
Ext3.2 TAGATAGCCC ATCATTGGCA TCACACTATA TGGATCTAAG CAGAAAGTGT MtN12 TAGATAGCCC ATAATTGGCA TCACACCATA TGGATCTAAA CAGAAAGTGT
\end{abstract}

Ext3.2 GAAAGCAGAG AAAGCCATGA ACAACGAATA CCGAGGGGAT TCTTCACATA MtN12 GAAAGCAAAG AAAGCCATGC ACAAAGAAGA TCAAGGGGAT TCTTCAC..A $\begin{array}{ll}\text { Ext } 3.2 & \text { TATATTCGT CAGTCTTTGA TTAATATTGT TGAGAGGGTT GCTTTPATT. } \\ \text { MtN12 TATATTTCGT CAGCATTTGA TPAAGATTGT TTAGAGGGCI CCGTTATTT }\end{array}$

Ext3.2 .TATTTAATT TGTGTPTITA TTGTATTAGC CACAACTGTA AGGCACTGCC MtN12 GTATTTAATT TGTGTTITIG TTGTATTATE CACAGCTGTA AGGCACTGCC

Ext3.2 CCAATATGCA TGTO.CTGCA GTTGTTTGCA TAAATIGTAA TTRTCAAAGT MtN12 CCAATATGCA TGTGTCIGCA GTTGTTITCA TGCATTGTAA TTTTCAAAGT Ext3.2 TTGGTTITTG TATCACGCTG ACTGACAAGC CAAATAA. A TATATCCCCT
MtN12

Ext3.2 ATTATAGTAA AAAAAAAAAA AAAAAAAAA MtN12 ATTATAGTAA AAAAAAAAAT AAAAAAA

Fig. 7. Comparison of the $3^{\prime}$-untranslated regions from the UAG stop codon to the polyA region for matrix glycoprotein clone PsEXT3.2 and MtN12 (Gamas et al. 1996). Identical alignments are shaded. 


\section{Electron microscopy.}

Samples were prepared for electron microscopy as previously described (Sherrier et al. 1997). Monoclonal antibody MAC265 (rat immunoglobulin class IgG) was used to localize MGP in tissue sections from root nodules (VandenBosch et al. 1989).

\section{Immunoaffinity purification of MGP.}

The immunoaffinity column was prepared as follows. A sample of MAC265 hybridoma culture supernatant $(30 \mathrm{ml})$ was mixed with $1 \mathrm{ml}$ of Protein $\mathrm{G}$ Sepharose beads (Amersham Pharmacia Biotech, Uppsala, Sweden) overnight at $4{ }^{\circ} \mathrm{C}$ in 50 $\mathrm{mM}$ Tris- $\mathrm{HCl}, \mathrm{pH} \mathrm{7.4}$, and $200 \mathrm{mM} \mathrm{NaCl}$ (TBS). To bind the antibody covalently, the beads were washed and resuspended in $200 \mathrm{mM}$ sodium borate, $\mathrm{pH} 9.0$, containing $20 \mathrm{mM}$ dimethylpimelimidate for $30 \mathrm{~min}$ at room temperature. Excess sites were blocked by washing the beads with $200 \mathrm{mM}$ ethanolamine, $\mathrm{pH} 8.0$, and incubating them in fresh buffer for $2 \mathrm{~h}$. Unbound antibody was removed with $200 \mathrm{mM}$ glycine, $\mathrm{pH} 2.8$. Finally, the beads were washed with several changes of TBS. All incubations were mixed gently on a rocking table (Luckham, Sussex, U.K.).

Plant debris and agar was removed by filtering the root exudate through one layer of glass fiber (Whatman International Ltd., Maidstone, U.K.) plus two layers of filter paper (Whatman No. 1). The filtrate was mixed with the Protein G Sepharose coupled with MAC265 and stirred on ice for $2 \mathrm{~h}$. The beads were collected by centrifugation at $2,000 \times g$ for 5 min, transferred to a disposable column (Bio-Rad Poly-Prep Columns; Bio-Rad, Hercules, CA, U.S.A.), and washed with 2 $\mathrm{ml}$ extraction buffer followed by $7 \mathrm{ml}$ TBS containing $10 \mathrm{mM}$ ascorbate. MGP was eluted from the column with $5 \mathrm{ml}$ of 100 $\mathrm{mM}$ glycine, $\mathrm{pH} 2.8$, and $10 \mathrm{mM}$ ascorbate. Five 1-ml fractions were collected into tubes containing $100 \mu \mathrm{l}$ of $1 \mathrm{M}$ Tris- $\mathrm{HCl}$, $\mathrm{pH}$ 9.0. The presence of MAC265 antigen in each fraction was established by dot assay as below. Fractions containing MGP were desalted and concentrated by centrifugation through a Centricon concentrator (Amicon Inc., Beverly, MA, U.S.A.) according to the manufacturer's instructions. The final volume $(100 \mu \mathrm{l})$ was stored at either $4^{\circ} \mathrm{C}$ or $-70^{\circ} \mathrm{C}$.

MGP was purified from nodules as above, except that $1 \mathrm{~g}$ nodules were homogenized in a pestle and mortar on ice in $10 \mathrm{ml} \mathrm{ex}$ traction buffer and the homogenate was squeezed through Miracloth (Calbiochem, San Diego, CA, U.S.A.) prior to filtration.

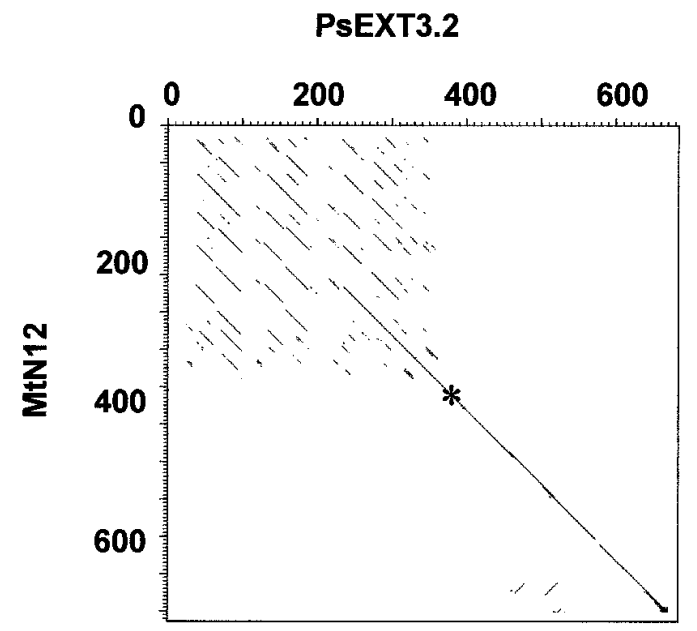

Fig. 8. Diagon (dot) plot of DNA sequences from PsEXT3.2 and MtN12. Pairwise scores are averaged over a default width of 25 residues (Sonnhammer and Durbin 1999). The position of the stop codon is indicated by an asterisk.

\section{SDS-PAGE and immunoblotting}

The purified materials were separated by SDS-PAGE on discontinuous $10 \%(\mathrm{wt} / \mathrm{vol}$ ) acrylamide gels (Wisniewski et al. 2000) using the Bio-Rad mini-Protean system at $100 \mathrm{~V}$, for 60 to $90 \mathrm{~min}$. The samples were not routinely boiled nor was reducing agent added to the sample buffer, since neither method altered the way that the samples separated. MGP was visualized by staining with silver after oxidation with sodium $m$-periodate as described by Wood and associates (1989).

Gels were blotted to nitrocellulose membranes overnight in $10 \mathrm{mM}$ 3-[cyclohexylamino]-1-propanesulfonic acid buffer, $\mathrm{pH}$ $11.0,10 \%$ (vol/vol) methanol using the Bio-Rad mini-Protean system at $9 \mathrm{~V}$. After washing with TBS, the nitrocellulose was blocked with $0.1 \%$ (vol/vol) Tween 20 for $15 \mathrm{~min}$, incubated with MAC265 (LM1 or buffer) for $2 \mathrm{~h}$ at room temperature or overnight at $4{ }^{\circ} \mathrm{C}$ followed by anti-rat IgG conjugated with alkaline phosphatase (Sigma, Poole, U.K.), and visualized with substrate as described by Wood and associates (1989).

\section{FTIR analysis.}

MGP extracted from 300 pea seedlings was desalted and concentrated to a final volume of $85 \mu \mathrm{l}$. An aliquot $(30 \mu \mathrm{l})$ of this material was dried under vacuum for FTIR analysis. (The sample did not dry down completely, but a sticky residue remained.) Analysis was done on a Bio-Rad FTS 40 spectrophotometer with microscope accessory at $8 \mathrm{~cm}^{-1}$ resolution with 128 interferograms coadded as described by Chen and associates (1998).

\section{Chymotrypsin treatment and protein sequencing.}

Desalted concentrated MGP from over 3,000 pea seedlings was pooled, further concentrated, and treated with $0.75 \mu \mathrm{g}$ sequencing grade chymotrypsin (F. Hoffmann-La Roche Ltd., Basel, Switzerland) in $20 \mu \mathrm{l}$ of $100 \mathrm{mM}$ Tris- $\mathrm{HCl}, \mathrm{pH} 7.8,10$ $\mathrm{mM} \mathrm{CaCl}{ }_{2}$ or buffer alone overnight at $28^{\circ} \mathrm{C}$. The digested material was separated by SDS-PAGE and blotted as before, except that the gel was prerun with $100 \mathrm{mM}$ sodium thioglycollate and blotted to polyvinylidene diflouride (PVDF) membranes (ProBlott; Applied Biosystems, Foster City, CA, U.S.A.). The PVDF blot was stained with $0.1 \%$ (wt/vol) Coomassie Blue R250 in 50\% (vol/vol) methanol and briefly washed with $50 \%$ (vol/vol) methanol. Sequencing grade chemicals and water were used throughout to minimize blocking of the protein N-terminus. The $40-\mathrm{kDa}$ band was cut from the blot and sequenced using pulsed-liquid mode on a Model 494 Procise protein sequencer (Applied Biosystems, Warrington,

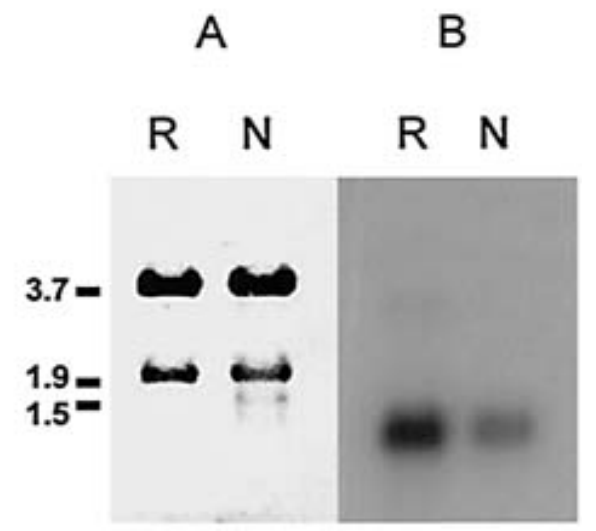

Fig. 9. Northern blot showing RNA from uninoculated pea roots $(\mathrm{R})$ and pea nodules (N) A, on a nylon membrane stained with methylene blue to visualize ribosomal RNA, and B, probed with PsEXT3.2 DNA. The sizes (in $\mathrm{kb}$ ) indicate the positions of $25 \mathrm{~S}$ and $18 \mathrm{~S}$ plant rRNA and $16 \mathrm{~S}$ bacterial rRNA (the latter present only in nodules). 
Cheshire, U.K.). Similarity between the peptide sequences was established using the BLASTP programs of Altschul and associates (1997).

\section{Cloning, DNA sequencing, and analysis.}

Roots were inoculated as previously described and were harvested 14 days postinoculation (dpi); nodules were harvested at 14 dpi. Total RNA was isolated as described by Wisniewski and associates (2000). Enrichment for mRNA was either with oligo-dT beads (Dynal Biotech, Oslo, Norway) or an mRNA kit (Amersham Pharmacia Biotech).

Primers PER1 and PER2 (Table 1) were used in $3^{\prime}$-RACE with the oligo-d(T) adapter primer G1149 (Vincent at al. 2000) and inoculated root mRNA as template, following the method described by Frohman and associates (1988). Products were amplified by PCR using a 'nested' approach and AmpliTaq DNA polymerase (Perkin-Elmer Analytical Instruments, Beaconsfield, U.K.). The primer G1187 (Kardailsky and Brewin 1996), lacking the homopolymeric tail of G1149, was used as the reverse primer for the amplifications because of its higher annealing temperature. 5'-RACE used mRNA from nodules. A homopolymeric tail was added to the $5^{\prime}$ end of the first strand cDNA using terminal transferase (Amersham Pharmacia Biotech) so that G1149 could be used as forward primer for the second strand. PER3 and PER4 (Table 1, Fig. 5) were used as reverse primers. As before, G1149 was replaced with G1187 for amplification by PCR. RT-PCR used mRNA from uninoculated and inoculated roots and nodules, with PER13 and PER15 as forward and reverse primers (Table 1, Fig. 5). Reactions were carried out either in a PTC Thermal cycler (MJ Research Inc., Waltham, MA, U.S.A.) or a Techne Genius thermocycler (Techne, Cambridge, U.K.).

Products were cloned into the pCRII vector using the TA TOPO cloning kit (Invitrogen, San Diego, CA, U.S.A.). Sequencing reactions used Big Dye Terminator RR Mix (Applied Biosystems) and were sequenced on an automated ABI3377 DNA sequencer (Perkin-Elmer). DNA sequences were analyzed using the GCG Wisconsin Package version 10.1 (Genetics Computer Group, Madison, WI, U.S.A.).

\section{Northern and tissue blotting.}

Total RNA was isolated from pea nodules at 14 days postinfection and from whole roots of uninoculated pea plants of the same age as described above. Samples $(3.0 \mu \mathrm{g})$ of each RNA were run on a $1.0 \%$ (wt/vol) agarose denaturing gel containing 2.2 M formaldehyde in MOPS buffer (Ausubel et al. 1999) and blotted overnight to a Hybond-N nylon membrane (Amersham Pharmacia Biotech) by Northern blotting. Equality of RNA loading was confirmed by staining the membrane with $0.03 \%$ (wt/vol) methylene blue in $0.3 \mathrm{M}$ sodium acetate buffer, $\mathrm{pH} 5.2$.

PsEXT3.2 DNA was digested with EcoRI and PstI and separated on a $1.0 \%(\mathrm{wt} / \mathrm{vol})$ agarose gel. The required fragment was isolated and labeled with ${ }^{32} \mathrm{P} \alpha$-dCTP using the Rediprime II random prime labeling system (Amersham Pharmacia Biotech). Hybridization was overnight at $42^{\circ} \mathrm{C}$ in the presence of $50 \%(\mathrm{vol} / \mathrm{vol})$ formamide, with four low stringency washes at $42^{\circ} \mathrm{C}$ followed by two high stringency washes at $50^{\circ} \mathrm{C}$. Images were developed on Fuji Medical X-ray film (Fuji Photo Film Co., Tokyo, Japan).

Nodules harvested 3 weeks postinoculation were cut in half and printed on Hybond-N membrane (Perlick et al. 1997). The nodule blots were visualized with methylene blue (as described above) and photographed under a binocular Stemi SV8 microscope (Leica Microsystems Ltd., Milton Keynes, U.K.). The same membranes were then hybridized with PsEXT3.2 DNA (as described above) or with pBluescript DNA but without formamide. Images were developed as for Northern blots.

\section{ACKNOWLEDGMENTS}

We thank A. L. Rae for developing the original cytological analysis of MGP release from nodules, A. Edwards and P. Barratt for help with 3'and 5'-RACE, M. McCann for assistance with FTIR, J. L. Peart for production of monoclonal antibodies, J.-P. Knox for providing a sample of antiextensin antibody, and M. Crespi for advice on 3'-UTR structures. This work was supported by the UK-BBSRC.

\section{LITERATURE CITED}

Altschul, S. F., Madden, T. L., Schaffer, A. A., Zhang, J. H., Zhang, Z., Miller, W., and Lipman, D. J. 1997. Gapped BLAST and PSI-BLAST: A new generation of protein database search programs. Nucleic Acids Res. 25:3389-3402.

Arsenijevic-Maksimovic, I., Broughton, W. J., and Krause, A. 1997. Rhizobia modulate root-hair-specific expression of extensin genes. Mol. Plant-Microbe Interact. 10:95-101.

Ausubel, F. M., Brent, R., Kingston, R. E., Moore, D. D., Seidman, J. G., Smith, J. A., and Struhl, K. 1999. Current protocols in molecular biology. Wiley, New York.

Baumberger, N., Ringli, C., and Keller, B. 2001. The chimeric leucinerich repeat/extensin cell wall protein LRX1 is required for root hair morphogenesis in Arabidopsis thaliana. Genes Dev. 15:1128-1139.

Bolanos, L., Brewin, N. J., and Bonilla, I. 1996. Effects of boron on Rhizobium-legume cell-surface interactions and nodule development. Plant Physiol. 110:1249-1256.

Bradley, D. J., Wood, E. A., Larkins, A. P., Galfre, G., Butcher, G. W., and Brewin, N. J. 1988. Isolation of monoclonal-antibodies reacting with peribacteroid membranes and other components of pea root-nodules containing Rhizobium leguminosarum. Planta 173:149-160.

Bradley, D. J., Kjellbom, P., and Lamb, C. J. 1992. Elicitor-induced and wound-induced oxidative cross-linking of a proline-rich plant-cell wall protein - a novel, rapid defense response. Cell 70:21-30.

Brady, J. D., and Fry, S. C. 1997. Formation of di-isodityrosine and loss of isodityrosine in the cell walls of tomato cell-suspension cultures treated with fungal elicitors or $\mathrm{H}_{2} \mathrm{O}_{2}$. Plant Physiol. 115:87-92.

Brewin, N. J. 1991. Development of the legume root nodule. Ann. Rev. Cell Biol. 7:191-226.

Brewin, N. J. 1998. Tissue and cell invasion by Rhizobium. Pages $417-$ 429 in: The Rhizobiaceae. H. P. Spaink, A. Kondorosi, and P. J. J. Hooykaas, eds. Kluwer Academic Publishers, Dordrecht, The Netherlands.

Cassab, G. I. 1998. Plant cell wall proteins. Annual Review of Plant Physiol. Plant Mol. Biol. 49:281-309.

Chen, L. M., Carpita, N. C., Reiter, W. D., Wilson, R. H., Jeffries, C., and McCann, M. C. 1998. A rapid method to screen for cell-wall mutants using discriminant analysis of Fourier transform infrared spectra. Plant J. 16:385-392.

Crespi, M. D., Jurkevitch, E., Poiret, M., d'Aubenton-Carafa, Y., Petrovics, G., Kondorosi, E., and Kondorosi, A. 1996. Enod40, a gene expressed during nodule organogenesis, codes for a non-translatable RNA involved in plant growth. EMBO (Eur. Mol. Biol. Organ.) J. 13:5099-5112.

de Lorenzo, C. A., Fernandez-Pascual, M. M., and de Felipe, M. R. 1998. Subcellular localization of glycoprotein epitopes during the development of lupin root nodules. Protoplasma 201:71-84.

Derrigo, M., Cestelli, A., Savettieri, G., and Di Liegro, I. 2000. RNA-protein interactions in the control of stability and localization of messenger RNA (review). Int. J. Mol. Med. 5:111-123.

Emanuelsson, O., Nielsen, H., Brunak, S., and von Heijne, G. 2000. Predicting subcellular localization of proteins based on their N-terminal amino acid sequence. J. Mol. Biol. 300:1005-1016.

Frohman, M. A., Dush, M. K., and Martin, G. R. 1988. Rapid production of full-length cDNAs from rare transcripts - amplification using a single gene-specific oligonucleotide primer. Proc. Natl. Acad. Sci. U.S.A. 85:8998-9002.

Gage, D. J., Bobo, T., and Long, S. R. 1996. Use of green fluorescent protein to visualize the early events of symbiosis between Rhizobium meliloti and alfalfa (Medicago sativa). J. Bacteriol. 178:7159-7166.

Gamas, P., de Carvalho Niebel, F., Lescure, N., and Cullimore, J. V. 1996. Use of a subtractive hybridization approach to identify new Medicago truncatula genes induced during root nodule development. Mol. PlantMicrobe Interact. 9:233-242.

Gardner, C. D., Sherrier, D. J., Kardailsky, I. V., and Brewin, N. J. 1996. Localization of lipoxygenase proteins and mRNA in pea nodules: Identification of lipoxygenase in the lumen of infection threads. Mol. Plant-Microbe Interact. 9:282-289.

Higashi, S., Kushiyama, K., and Abe, M. 1987. Electron microscopic observations of infection threads in driselase treated nodules of Astraga- 
lus sinicus. Can. J. Microbiol. 32:947-952.

Kardailsky, I. V., and Brewin, N. J. 1996. Expression of cysteine protease genes in pea nodule development and senescence. Mol. Plant-Microbe Interact. 9:689-695.

Kieliszewski, M. J., and Lamport, D. T. A. 1994. Extensin: Repetitive motifs, functional sites, post-translational codes, and phylogeny. Plant J. 5:157-172

Long, S. R. 1996. Rhizobium symbiosis: Nod factors in perspective. Plant Cell 8:1885-1898.

McCann, M. C., Chen, L. M., Roberts, K., Kemsley, E. K., Sene, C. Carpita, N. C., Stacey, N. J., and Wilson, R. H. 1997. Infrared microspectroscopy: Sampling heterogeneity in plant cell wall composition and architecture. Physiologia Plantarum 100:729-738.

Moulin, L., Munive, A., Dreyfus, B., and Boivin-Masson, C. 2001. Nodulation of legumes by members of the beta-subclass of Proteobacteria. Nature 411:948-950.

Nielsen, H., Engelbrecht, J., Brunak, S., and vonHeijne, G. 1997. Identification of prokaryotic and eukaryotic signal peptides and prediction of their cleavage sites. Protein Eng. 10:1-6.

O’Neill, M. A., Eberhard, S., Albersheim, P., and Darvill, A. G. 2001. Requirement of borate cross-linking of cell wall rhamnogalacturonan II for Arabidopsis growth. Science 294:846-849.

Otte, O., and Barz, W. 2000. Characterization and oxidative in vitro cross-linking of an extensinlike protein and a proline-rich protein purified from chickpea cell walls. Phytochem. 53:1-5.

Pellock, B. J., Cheng, H. P., and Walker, G. C. 2000. Alfalfa root nodule invasion efficiency is dependent on Sinorhizobium meliloti polysaccharides. J. Bacteriol. 182:4310-4318.

Perlick, A. M., and Puhler, A. 1993. A survey of transcripts expressed specifically in root-nodules of broadbean ( $V$. faba L.). Plant Mol. Biol. 22:957-970.

Perlick, A. M., Kuster, H., and Puhler, A. 1997. Analysis of genes expressed in root nodules of broad bean $(V$. faba L.). Pages 91-94 in: Biological Fixation of Nitrogen for Ecology and Sustainable Agriculture. A. Legocki, H. Bothe, and A. Puhler, eds. Springer-Verlag, Berlin.

Perotto, S., Brewin, N. J., and Kannenberg, E. L. 1994. Cytological evidence for a host defense response that reduces cell and tissue invasion in pea nodules by lipopolysaccharide-defective mutants of Rhizobium leguminosarum strain 3841. Mol. Plant-Microbe Interact. 7:99-112.

Peters, W. S., Hagemann, W., and Tomos, A. D. 2000. What makes plants different? Principles of extracellular matrix function in 'soft' plant tissues. Comp. Biochem. Physiol. A Mol. and Integr. Physiol. 125:151167.

Rae, A. L., Perotto, S., Knox, J. P., Kannenberg, E. L., and Brewin, N. J. 1991. Expression of extracellular glycoproteins in the uninfected cells of developing pea nodule tissue. Mol. Plant-Microbe Interact. 4:563570

Rae, A. L., Bonfantefasolo, P., and Brewin, N. J. 1992. Structure and growth of infection threads in the legume symbiosis with Rhizobium leguminosarum. Plant J. 2:385-395.

Santos, R., Herouart, D., Puppo, A., and Touati, D. 2000. Critical protective role of bacterial superoxide dismutase in Rhizobium-legume symbiosis. Mol. Microbiol. 38:750-759.

Santos, R., Herouart, D., Sigaud, S., Touati, D., and Puppo, A. 2001. Oxidative burst in alfalfa-Sinorhizobium meliloti symbiotic interaction. Mol. Plant-Microbe Interact. 14:86-89.

Schauser, L., Roussis, A., Stiller, J., and Stougaard, J. 1999. A plant regulator controlling development of symbiotic root nodules. Nature 402:191-195.

Scheres, B., van Engelen, F., van der Knap, E., van de Wiel, C., van Kammen, A., and Bisseling, T. 1990a. Sequential induction of nodulin gene expression in the developing pea nodule. Plant Cell 2:687-700.

Scheres, B., van de Wiel, C., Zalensky, A., Horvath, B., Spaink, H. P., van
Kammen, A., and Bisseling, T. 1990b. The ENOD12 gene product is involved in the infection process during the pea-Rhizobium interaction. Cell 60:281-294.

Schmidt, J. S., Lindstrom, J. T., and Vodkin, L. O. 1994. Genetic length polymorphisms create size variation in proline-rich proteins of the cell wall. Plant J. 6:177-186.

Schultze, M., and Kondorosi, A. 1998. Regulation of symbiotic root nodule development. Annu. Rev. Genet. 32:33-57.

Sherrier, D. J., and VandenBosch, K. A. 1994. Localization of repetitive proline-rich proteins in the extracellular-matrix of pea root-nodules. Protoplasma 183:148-161.

Sherrier, D. J., Borisov, A. Y., Tikhonovich, I. A., and Brewin, N. J. 1997. Immunocytological evidence for abnormal symbiosome development in nodules of the pea mutant line Sprint2Fix $\left(^{-}\right)$(sym31). Protoplasma 199:57-68.

Showalter, A. M. 1993. Structure and function of plant cell wall proteins. Plant Cell 5:9-23.

Smallwood, M., Beven, A., Donovan, N., Neill, S. J., Peart, J., Roberts, K., and Knox, J. P. 1994. Localization of cell-wall proteins in relation to the developmental anatomy of the carrot root apex. Plant J. 5:237246.

Sommer-Knudsen, J., Bacic, A., and Clarke, A. E. 1998. Hydroxyprolinerich plant glycoproteins. Phytochem. 47:483-497.

Sonnhammer, E. L. L., and Durbin, R. 1999. A dot-matrix program with dynamic threshold control suited for genomic DNA and protein sequence analysis. Gene 167:1-10.

Spaink, H. P. 2000. Root nodulation and infection factors produced by rhizobial bacteria. Annu. Rev. Microbiol. 54:257-288.

Sprent, J. I. 2001. Nodulation in legumes. Cromwell Press, London.

Stougaard, J. 2000. Regulators and regulation of legume root nodule development. Plant Physiol. 124:531-540.

Van Brussel, A. A. N., Bakhuizen, R., van Spronsen, P. C., Spaink, H. P., Tak, T. K., Lugtenberg, B. J. J., and Kijne, J. W. 1992. Induction of preinfection thread structures in the leguminous host plant by mitogenic lipo-oligosaccharides of Rhizobium. Science 257:70-72.

VandenBosch, K. A., Bradley, D. J., Knox, J. P., Perotto, S., Butcher, G. W., and Brewin, N. J. 1989. Common components of the infection thread matrix and the intercellular space identified by immunocytochemical analysis of pea nodules and uninfected roots. EMBO (Eur. Mol. Biol. Organ.) J. 8:335-341.

Vasse, J., Debilly, F., and Truchet, G. 1993. Abortion of infection during the Rhizobium meliloti-alfalfa symbiotic interaction is accompanied by a hypersensitive reaction. Plant J. 4:555-566.

Vincent, J. L., Knox, M. R., Ellis, T. H. N., Kaló, P., Kiss, G. B., and Brewin, N. J. 2000. Nodule-expressed Cyp15a cysteine protease genes map to syntenic genome regions in Pisum and Medicago spp. Mol. Plant-Microbe Interact. 13:715-723.

Wang, T. L., Wood, E. A., and Brewin, N. J. 1982. Growth-regulators, rhizobium and nodulation in peas - indole-3-acetic-acid from the culture-medium of nodulating and nonnodulating strains of $R$. leguminosarum. Planta 155:345-349.

Wisniewski, J. P., Rathbun, E. A., Knox, J. P., and Brewin, N. J. 2000. Involvement of diamine oxidase and peroxidase in insolubilization of the extracellular matrix: Implications for pea nodule initiation by Rhizobium leguminosarum. Mol. Plant-Microbe Interact. 13:413-420.

Wojtaszek, P., Trethowan, J., and Bolwell, G. P. 1997. Reconstitution in vitro of the components and conditions required for the oxidative cross-linking of extracellular proteins in French bean (Phaseolus vulgaris L.). FEBS (Fed. Eur. Biochem. Soc.) Lett. 405:95-98.

Wood, E. A., Butcher, G. W., Brewin, N. J., and Kannenberg, E. L. 1989. Genetic derepression of a developmentally regulated lipopolysaccharide antigen from Rhizobium leguminosarum 3841. J. Bacteriol. 171:4549-4555. 